\title{
A Low-Cost Preparation of Si@C Composite Anode from Si Photovoltaic Waste
}

\author{
Shiyun Zhang ${ }^{1}$, Jian Xie ${ }^{1,2, *}$, Chunyang $\mathrm{Wu}^{3}$, XinbingZhao ${ }^{1,2}$ \\ ${ }^{1}$ State Key Laboratory of Silicon Materials, School of Materials Science and Engineering, Zhejiang \\ University, Hangzhou 310027, P. R. China \\ ${ }^{2}$ Key Laboratory of Advanced Materials and Applications for Batteries of Zhejiang Province, \\ Hangzhou 310027, P. R. China \\ ${ }^{3}$ State Key Laboratory of Electronic Thin Films and Integrated Devices, University of Electronic \\ Science and Technology of China, Chengdu 610054, P. R. China \\ *E-mail: xiejian1977@zju.edu.cn
}

doi: $10.20964 / 2020.07 .24$

Received: 8 March 2020 / Accepted: 16 April 2020 / Published: 10 June 2020

Silicon materials are recognized as one of the most attractive anode materials in Li-ion batteries (LIBs) due to their ultrahigh capacity. However, there are still challenges to fabricate silicon-based anodes with a sustainable, scalable and cost-effective method. In this work, nanoscale Si was synthesized using the wafer slicing wastes from photovoltaic (PV) industry via a scalable and facile fabrication approach. After purification and sand milling, the obtained Si of 100-200 nm delivers a high discharge capacity of $2554 \mathrm{mAh} \mathrm{g}^{-1}$. To address the potential application of the nanoscale Si in practical LIBs, a silicon/carbon composite ( $\mathrm{Si} @ \mathrm{C}-\mathrm{G}$ ) was made, which is composed of the nanoscale $\mathrm{Si}$, artificial graphite, graphene and pyrolytic carbon. The $\mathrm{Si} @ \mathrm{C}-\mathrm{G}$ composite anode could yield a stable capacity of around $400 \mathrm{mAh} \mathrm{g}^{-1}$, and a high retention rate of $91 \%$ can be achieved after 100 cycles, where the introduced graphene provide a better conducting/buffering network. Our work shows the waste Si from PV industry can be recycled and reused in LIBs industry.

Keywords: Nano silicon, Si/C composite, Anode material, Photovoltaic waste silicon, Lithium-ion battery.

\section{$\underline{\text { FULL TEXT }}$}

(C) 2020 The Authors. Published by ESG (www.electrochemsci.org). This article is an open access article distributed under the terms and conditions of the Creative Commons Attribution license (http://creativecommons.org/licenses/by/4.0/). 